\title{
Desafios preponderantes na proteção dos mananciais no extremo Oeste Paulista
}

\author{
Major challenges in protecting springs in the far west of São Paulo
}

Grandes desafíos en la protección de manantiales en el extremo oeste de São Paulo

Giovanna Rocha Cristofoli

Graduanda em Engenharia Ambiental, UNESP, Brasil

giovanna.cristofoli@unesp.br

Lucas Cunha da Silva

Graduando em Engenharia Ambiental, UNESP, Brasil cunha.silva@unesp.br

Sandra Medina Benini

Docente da FCT/UNESP, Brasil. arquiteta.benini@gmail.com 


\title{
1 INTRODUÇÃO
}

Conforme Agência Nacional de Águas e Saneamento Básico - ANA (2017), que tem por uma de suas funções auxiliar na produção de planos de recursos hídricos, tem-se as seguintes definições relacionadas à gestão dos recursos hídricos:

\begin{abstract}
Previstos pela Política Nacional de Recursos Hídricos, os Planos de Recursos Hídricos são documentos que definem a agenda dos recursos hídricos de uma região, incluindo informações sobre ações de gestão, projetos, obras e investimentos prioritários. Além disso, fornecem dados atualizados que contribuem para o enriquecimento das bases de dados da Agência Nacional de Águas (ANA). A partir de uma visão integrada dos diferentes usos diferentes usos da água, os planos são elaborados em três níveis: bacia hidrográfica, nacional e estadual. Contam também com o envolvimento de órgãos governamentais, da sociedade civil, dos usuários e de diversas instituições que participam do gerenciamento dos recursos hídricos. ${ }^{1}$
\end{abstract}

A degradação dos recursos hídricos ainda persistente na contemporaneidade, em determinados momentos e localidades de forma mais intensificada, é um dos pontos mais alarmantes correlativos a deterioração dos recursos naturais. Compreender os métodos atuais adotados bem como os obstáculos para a proteção de determinado manancial, é primordial para que futuras análises e propostas de intervenções possam ser engendradas

\section{OBJETIVO}

Este artigo tem por objetivo compreender os desafios preponderantes na proteção do manancial na bacia do Rio Santo Anastácio.

\section{ESTUDO DE CASO}

O Estudo de caso foi realizado com base nos estudos desenvolvidos por Stein, Ponçano e Saad (2003); Carpi Junior e Leal (2012); Dibieso (2013) e Mota e Pereira (2015).

A Bacia Hidrográfica do Alto Curso do Rio Santo Anastácio se destaca no Oeste Paulista por ser uma das responsáveis pelo abastecimento público. Essa Bacia Hidrográfica está localizada na Unidade de Gerenciamento de Recursos Hídricos do Pontal do Paranapanema UGRHI-22 (MOTA; PEREIRA, 2015).

Possuindo uma área de 19.830,00 ha, a bacia além de abranger parte dos Municípios de Presidente Prudente, Pirapozinho, Regente Feijó, Anhumas e Álvares Machado e ser interceptada pelas rodovias Assis Chateubriand, Raposo Tavares, e Júlio Budiski (MOTA; PEREIRA, 2015).

A localização da Bacia Hidrográfica do Alto Curso do Rio Santo Anastácio pode ser observada na Figura I.

1 Disponível em: https://www.gov.br/ana/pt-br/assuntos/gestao-das-aguas/politica-nacional-de-recursoshidricos/planos-de-recursos-hidricos Acesso 07 ago. 2021. 
Figura I - Localização da Bacia Hidrográfica do Alto Curso do Rio Santo Anastácio

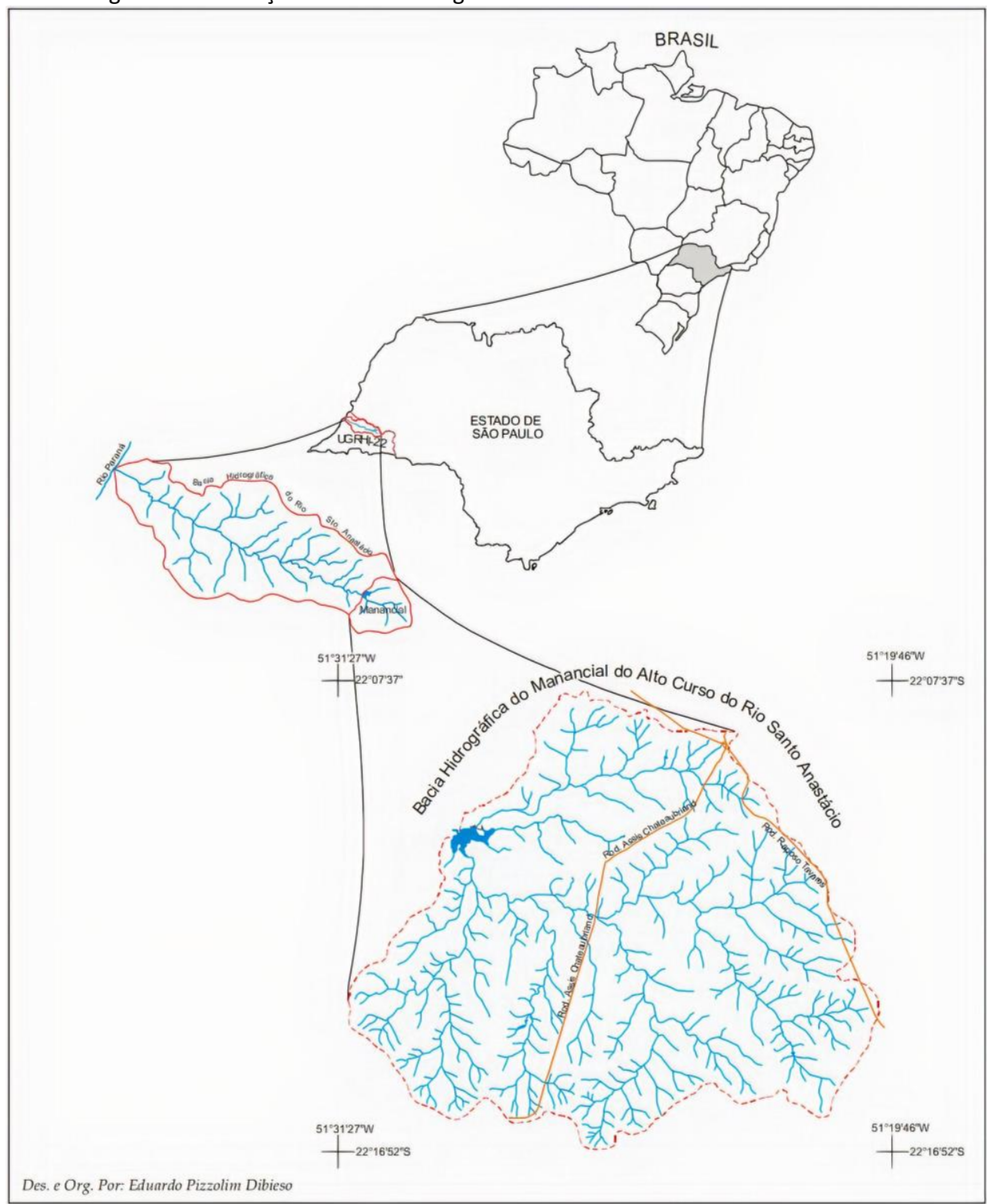

Fonte: Dibieso, 2013

O manancial do alto curso do Rio Santo Anastácio é responsável pelo abastecimento público de aproximadamente 30\% do município de Presidente Prudente - SP (DIBIESO, 2013). Apesar disso, essa bacia hidrográfica apresenta vários problemas ambientais, como desmatamento, ocupação irregular em áreas de preservação permanente, rios assoreados e erosão, impactos esses que foram causados tanto por pastagens, como por expansão urbana, o que infere em um forte risco ambiental em relação a situação de seus rios e de seu manancial (MOTA; PEREIRA, 2015).

De acordo com Stein, Ponçano e Saad (2003) no estudo sobre os processos erosivos na bacia do rio Santo Anastácio, essa bacia hidrográfica se destacou como sendo a mais suscetível e também a mais comprometida pelos processos erosivos, o que resultou em um impacto ambiental sobre os recursos hídricos.

A região conturbada de Presidente Prudente é de longe a mais problemática, pois alia as piores situações de meio físico natural e de ocupação. Sua expansão continua mantendo procedimentos ditados por projetos de urbanização que priorizam um máximo aproveitamento da área em detrimento de cuidados mínimos com 


\title{
Revista Científica ANAP Brasil
}

ISSN 1984-3240 - Volume 14, número 35, 2021

\begin{abstract}
adequações que considerem a preservação ambiental. Aliam-se, aqui, os graves problemas de disponibilidade de água para consumo público e o lançamento de esgotos in natura nos próprios mananciais, pressionados ainda pela expansão dos bairros periféricos. O recurso hídrico subterrâneo, de aqüíferos livres e profundos, é explorado sem controle, bem como não há preocupações com sua poluição, situações que podem acarretar comprometimentos irreversíveis aos aqüíferos (STEIN; PONÇANO; SAAD, 2003).
\end{abstract}

No tocante aos despejos de esgoto, Carpi Junior e Leal (2012, p. 1494) salientam que embora "a situação tenha melhorado nos últimos anos, com a construção da Estação de Tratamento de Esgoto, persistem casos de lançamentos clandestinos".

Em relação a ocupação das áreas participativas da bacia do Rio Santo Anastácio, principalmente no município de Presidente Prudente, tem-se:

\begin{abstract}
Sabe-se que a região de Presidente Prudente é considerada como a mais problemática ambientalmente, pois alia as piores situações de meio físico natural e de ocupação, com a contínua expansão urbana mantendo procedimentos ditados por projetos de urbanização que priorizam um máximo aproveitamento da área em detrimento de cuidados mínimos e adequações que considerem a preservação ambiental. É o caso da sub-bacia do Córrego do Cedro, onde a impermeabilização do solo da área urbanizada, associada à alta suscetibilidade à erosão dos solos, torna este setor um dos mais ambientalmente frágeis da bacia hidrográfica do manancial rio Santo Anastácio (CARPI JUNIOR; LEAL, 2012).
\end{abstract}

Ocorrem ainda casos de ocupação irregular em áreas de preservação e proteção ambiental:

\begin{abstract}
Segundo Dibieso (2007), a análise da distribuição espacial dos principais impactos ambientais da bacia hidrográfica do Córrego do Cedro, localizada em Presidente Prudente, demonstra uma dinâmica de ocupação intensa e irregular, como, por exemplo, das áreas de preservação e proteção ambiental para uso e ocupação do solo para fins urbanos e pastagens. $O$ autor salienta que após esta caracterização, a bacia do Cedro demonstrou ser uma área onde são necessárias medidas urgentes de planejamento ambiental, em especial as de disciplinamento do uso e de ocupação do solo, pela forte expansão urbana que vem sofrendo nos últimos anos. (apud CARPI JUNIOR; LEAL, 2012).
\end{abstract}

A legislação para proteção de mananciais, tem-se o Decreto Federal № 24.643/1934, também conhecido como o código de águas que mesmo tendo sido promulgado em 1934 é ainda considerado como avançado, assim como a Lei Federal № 9433/1997 que promulgou a Política Nacional de Recursos Hídricos, também conhecida como Lei das Água.

Em relação ao que se tem disponível em termos de legislação estadual para a proteção de mananciais, no estado de São Paulo se destaca a Lei № 7.663/1991 que promulgou a Política Estadual de Recursos Hídricos e o Sistema Integrado de Gerenciamento de Recursos Hídricos, a Lei № 898/1975 e a Lei № 1.172/1976 e pelo Decreto № 9.714/1977 que a regulamenta.

Já em relação à legislação de proteção e recuperação de bacias hidrográficas dos mananciais, tem-se a Lei Estadual № 9.866/1997 que foi regulamentada pelo Decreto Estadual № 43.022/1998.

Ainda, está previsto na Lei no 9.866/1997 a definição de Área de Proteção e Recuperação dos Mananciais - APRM, considerando-se uma ou mais sub-bacias hidrográficas dos mananciais de interesse regional para abastecimento público. As APRMs serão definidas e delimitadas mediante proposta do Comitê de Bacia Hidrográfica e por deliberação do Conselho Estadual de Recursos Hídricos - CRH, 
ouvidos o CONSEMA - Conselho Estadual de Meio Ambiente e o CDR - Conselho de Desenvolvimento Regional e deverão estar inseridas em uma das vinte e duas Unidades de Gerenciamento de Recursos Hídricos do Estado de São Paulo (DIBIESO, 2013).

Em consonância com Teixeira et al. (2009) tem-se os seguintes aspectos relativos à legislação:

Há um excesso de crença na força da lei, acompanhada pela fragilidade das instituições que deveriam aplicá-la. Também, como um todo, o arcabouço jurídico é especializado em dimensões isoladas (ar, água, solo, florestas, etc.) com muitas lacunas e conflitos. Consequentemente, as normas não induzem o comportamento coletivo, conforme esperado, o que fica patente no caso da ocupação irregular.

Entende-se então que devido ocorrer uma fragmentação na fiscalização da lei, tendo em vista os recursos ambientais, nota-se que não há uma efetividade alta, tendo em mente que aspectos ainda latentes como a ocupação irregular são observados.

\section{METODOLOGIA}

O procedimento a ser implementado foi baseado no modo de pesquisa de Teixeira et al. $^{2}$ (2009) onde mescla-se a pesquisa-ação e o estudo de caso, isto é, a partir da análise que engloba essas temáticas, faz-se possível entender como ocorre a proteção de determinado manancial designado, bem como outros aspectos que margeiam o ponto em questão. Conforme a Figura II, observa-se a metodologia implementada no atual estudo.

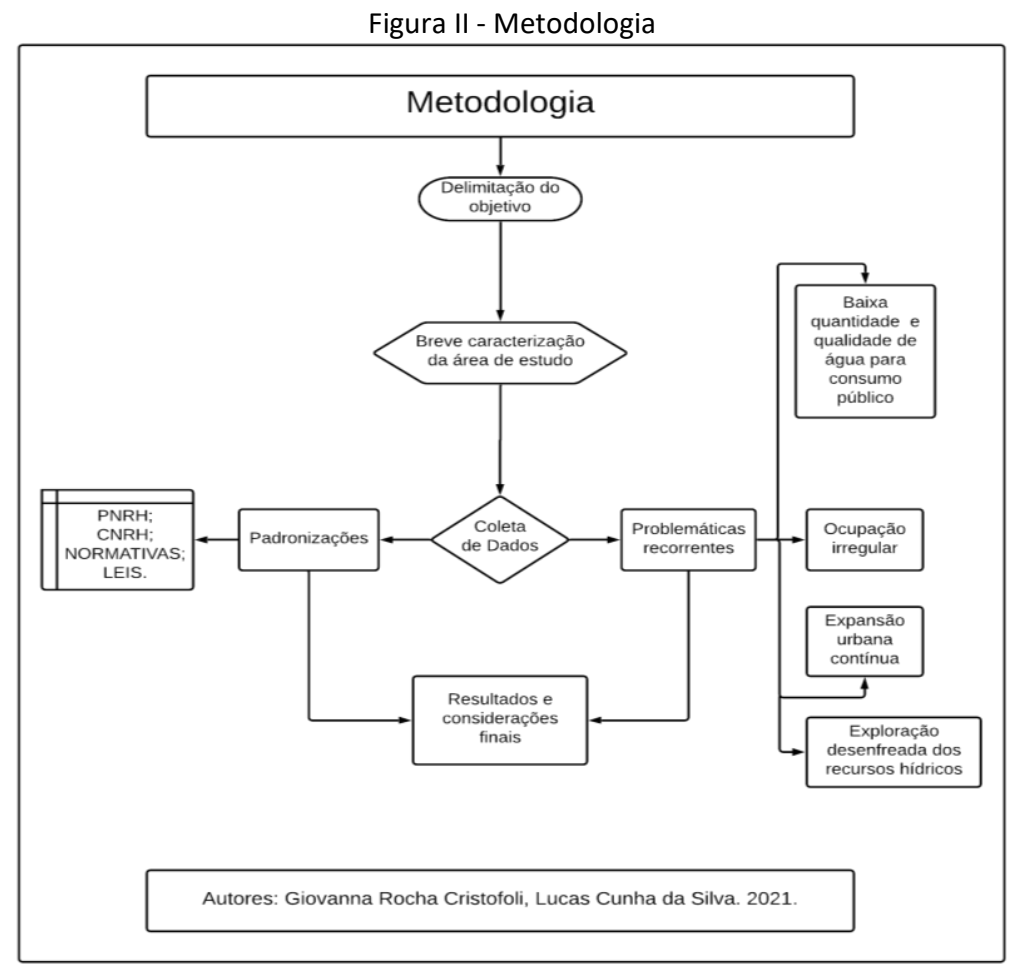

Fonte: Autores, 2021.

\footnotetext{
2 Teixeira et al. baseia-se em Clegg (1999) e Yin (1994) para desenvolver essa metodologia. Acessível em: RAI Revista de Administração e Inovação, São Paulo, v. 6, n. 3, p.94-107, set./dez. 2009.
} 


\section{RESULTADOS E DISCUSSÕES}

Após as abordagens inseridas nos tópicos anteriores, depreende-se que o modo segmentado de como é a atual legislação tende a dificultar a fiscalização da lei. Teixeira et al. (2009) fala ainda sobre o estudo de caso a caso, exigindo assim a inserção de uma alta gama de recursos, inviabilizando o processo e impedindo o avanço no controle da degradação dos recursos naturais, em específico o recurso hídrico.

Observa-se que a existência de ocupações irregulares e indevidas na bacia do Rio Santo Anastácio, bem como outras problemáticas recorrentes, comprova que existe alguma perturbação em questão. A partir do presente estudo, compreende-se que alguns dos principais obstáculos prevalecentes durante a aplicação da proteção do manancial relativo à bacia do Rio Santo Anastácio, são as aplicações legislativas fragmentadas e o alto custo para a fiscalização.

\section{CONSIDERAÇÕES FINAIS}

Percebe-se que a temática de proteção aos mananciais é de suma importância para uma preservação e conservação mais assídua dos recursos hídricos, estudos e análises que mostram como está ocorrendo esse tipo de proteção auxilia futuras ações a serem tomadas e implementadas, tendo isso em vista, confere-se ao atual estudo essa determinada importância.

Nota-se que foi exequível a averiguação dos impasses ainda recorrentes relativos à proteção da bacia hidrográfica do rio Santo Anastácio, permitindo assim, a adoção de medidas citadas no parágrafo anterior. Conferindo assim, um caráter emergencial de planejamento para a região.

\section{REFERENCIAL BIBLIOGRÁFICO}

AGÊNCIA NACIONAL DE ÁGUAS E SANEAMENTO BÁSICO - ANA. Planejamento dos recursos hídricos. Disponível em: https://www.ana.gov.br/gestao-da-agua/planejamento-dos-recursos-hidricos. Acesso em: 06 de Julho de 2021.

BRASIL. Lei no. 9.433, de 8 de janeiro de 1997. Institui a Política Nacional de Recursos Hídricos e cria o Sistema Nacional de Gerenciamento de Recursos Hídricos. Brasília: Palácio do Planalto. Disponível em: http://www.planalto.gov.br/ccivil_03/leis/19433.htm. Acesso em: 06 de Julho de 2021.

CONSELHO NACIONAL DE RECURSOS HÍDRICOS. Resolução CNRH №145, de 12 de dezembro de 2012. Disponível em: https://www.ceivap.org.br/ligislacao/Resolucoes-CNRH/Resolucao-CNRH\%20145.pdf. Acesso em: 06 de Julho de 2021.

CARPI JUNIOR, S.; LEAL, A. C. Mapeamento de Riscos Ambientais e Planejamento Participativo no Manancial Rio Santo Anastácio - UGRHI do Pontal do Paranapanema - São Paulo. Revista Geonorte, Edição Especial, V.3, N.4, p.1495-1507, 2012. Disponível em: https://www.periodicos.ufam.edu.br/index.php/revistageonorte/article/view/2044. Acesso em: 29 de julho de 2021.

DIBIESO, E. P. Planejamento ambiental e gestão dos recursos hídricos: estudo aplicado à bacia hidrográfica do manancial do alto curso do Rio Santo Anastácio - São Paulo/Brasil. Tese de Doutorado, Presidente Prudente: FCT/UNESP, 2013. Disponível em: https://repositorio.unesp.br/handle/11449/105072. Acesso em: 29 de julho de 2021.

MOTA, E.A.F.; PEREIRA, M.H. Proposta de Criação Da APRM - Área De Proteção e Recuperação de Manancial do Alto Curso da Bacia do Rio Santo Anastácio. Periódico eletrônico, v. 11, n. 06, p. 349-361, 2015. Disponível em: https://amigosdanatureza.org.br/publicacoes/index.php/forum_ambiental/article/view/1273. Acesso em: 29 de julho de 2021. 


\section{Revista Científica ANAP Brasil}

ISSN 1984-3240 - Volume 14, número 35, 2021

SÃO PAULO. Lei no. 7.663 de 30 de dezembro de 1991. Estabelece as normas de orientação à Política Estadual de Recursos Hídricos e do Sistema Integrado de Gerenciamento de Recursos Hídricos. Disponível

em: https://www.al.sp.gov.br/repositorio/legislacao/lei/1991/lei-7663-30.12.1991.html. Acesso em: 06 de Julho de 2021.

STEIN, D. P.; PONÇANO, W. L.; SAAD, A. R. Erosão na bacia do Rio Santo Anastácio, oeste do Estado de São Paulo, Brasil. Geociências. São Paulo, UNESP, v. 22, n. 2, p. 143-162, 2003. Disponível

em: http://revistageociencias.com.br/geociencias-arquivos/22_2/4.pdf. Acesso em: 06 de Julho de 2021.

TEIXEIRA, H. J. ; TEIXEIRA, M. O. P. A.; MARTELANC, R. Desafios e inovações na proteção dos mananciais da região metropolitana de São Paulo . Disponível em: https://www.revistas.usp.br/rai/article/view/79151/83223 Acesso em: 5 de Julho de 2021. 